\title{
Exploring the perception of women with epilepsy about pregnancy concerns: a qualitative study
}

\author{
Zahra Atarodi-Kashani ${ }^{1}$, Nourossadat Kariman ${ }^{2}$, Abbas Ebadi ${ }^{3}$, Hamid Alavai Majd ${ }^{4}$, Nahid Beladi-Moghadam ${ }^{5}$, \\ Omid Hesami ${ }^{5}$
}

${ }^{1}$ Ph.D. Candidate of Reproductive Health, International Branch, Department of Midwifery and Reproductive Health, Nursing and Midwifery School, Shahid Beheshti University of Medical Sciences, Tehran, Iran

${ }^{2}$ Ph.D. of Reproductive Health, Assistant Professor, Midwifery and Reproductive Health Research Center, Faculty of Nursing and Midwifery, Shahid Beheshti University of Medical Sciences, Tehran, Iran

${ }^{3}$ Ph.D. of Nursing Education, Associate Professor, Behavioral Sciences Research Center, Life style Institute, Nursing Faculty, Baqiyatallah University of Medical Sciences, Tehran, Iran

${ }^{4}$ Ph.D. of Biostatistics, Professor, Faculty of Paramedical Sciences, Shahid Beheshti University of Medical Sciences, Tehran, Iran

${ }^{5}$ MD., Neurologist, Assistant Professor, Department of Neurology, Imam Hossein Hospital, Shahid Beheshti University of Medical Sciences, Tehran, Iran

\section{Type of article: Original}

\begin{abstract}
Background and aim: Epilepsy is a common neurological disorder in pregnancy, which is associated with increased maternal and fetal adverse outcomes. This study aimed to explore the reproductive healthcare needs of women with epilepsy before, during and after childbirth.

Methods: This was a qualitative study using a content analysis method. The study population was marital women with epilepsy in reproductive age (15-45 years) referred to Imam Hossein Hospital, Tehran, Iran. Participants were 16 women chosen using purposive sampling with the consideration of maximum variation in sampling. Semi-structured interviews were held with the participants until data saturation was reached. The data were analyzed using the content analysis method. The MAXQDA software, version 2010, was used for the management of data.

Results: The data analysis led to the development of two categories. The first one is named 'resilience against threats to safe pregnancy' and has the following subcategories: (1) real physical complications and perceived (mental) conditions due to unwanted pregnancies, (2) the predisposing factors of anxiety related to safe pregnancy, (3) perceived consequences of pregnancy', and (4) the approach to encounter perceived consequences of pregnancy. The second category is called 'adverse experiences under inefficient supportive systems' and has the following subcategories: (1) the insufficiency of reproductive healthcare services for women with epilepsy, (2) doubt about the advantages and disadvantages of breastfeeding, (3) stigma as a block to the treatment of the postpartum depression, and (4) playing the motherhood role under the shadow of self-esteem to lack of selfesteem.

Conclusion: In the prenatal, natal and postnatal duration, because of supportive system disruption and not receiving proper consultation, participants were often worried about not being able to get favorable conditions for safe pregnancy and controlling process of their pregnancy. Therefore, they often experienced unwanted pregnancy. They were also concerned about the adverse fetal outcomes. In postpartum period, they often experienced postpartum depression and were very doubtful about breastfeeding.
\end{abstract}

Keywords: Epilepsy, Pregnancy outcomes, Reproductive health, Need assessment

\section{Corresponding author:}

Assistant Professor Dr. Nourossadat Kariman, Midwifery and Reproductive Health Research Center, Shahid Beheshti University of Medical Sciences, Tehran, Iran.

Tel:+98.2188202512, Fax:+98. 2188202516, Email: n_kariman@sbmu.ac.ir and n_kariman@yahoo.com

Received: May 03, 2017, Accepted: August 06, 2017, Published: May 2018

iThenticate screening: August 07, 2017, English editing: March 05, 2018, Quality control: April 14, 2018

This article has been reviewed / commented by four experts

(C) 2018 The Authors. This is an open access article under the terms of the Creative Commons Attribution-NonCommercialNoDerivs License, which permits use and distribution in any medium, provided the original work is properly cited, the use is non-commercial and no modifications or adaptations are made. 


\section{Introduction}

The incidence of epilepsy in the world's population is $0.3-0.5 \%$ (1). There are no accurate statistics regarding the incidence of epilepsy in Iran. This disease occurs in 0.3 to $0.7 \%$ of women in the reproductive age $(2,3)$. Epilepsy is the most common neurological disorder in pregnancy with the prevalence of one case per 200 pregnancies. According to available studies, it is indicated that epilepsy threatens the mother by the adverse consequences of seizures during pregnancy. Also, taking certain anti-seizure drugs is associated with impaired fetal development (4). The high incidence of unplanned pregnancies in women with epilepsy and a lack of changes in the type of medication and adjustment of drug doses before pregnancy, increase the adverse consequences of epilepsy. The complications of epilepsy happens mainly in developing countries, which hinder women with epilepsy to receive critical care before and in the first trimester of pregnancy (5). Studies have shown that factors affecting unwanted pregnancy are the result of interactions between antiepileptic drugs and hormone contraceptive drugs (6). Also, there is a low percentage of contraceptive drugs' use compared with the general population $(53 \%$ vs. $75 \%)(7,8)$. Most women with epilepsy receive no education regarding drug interactions. Also, those women who experience unwanted pregnancy have a lower social-economic condition and know less or have misperceptions regarding the teratogenicity of drugs (9). Therefore, mothers' perceptions of drug use during pregnancy, exaggerated beliefs about the teratogenicity of anticonvulsant drugs and incorrect beliefs about the genetic identity of this disease (10), increase the number of primiparous women and selective abortion (11). Other important concerns of women with epilepsy during pregnancy are internal conflicts with medication in pregnancy (6) and concerns about breastfeeding during medication therapy (12). Given the above-mentioned problems, if women with epilepsy in the reproductive age are unable to make informed decisions on fertility issues, they may be faced with physical, mental and emotional challenges. According to evidence-based interventions using the application of predetermined instructions, it is impossible to overcome these women's problems and concerns (8). Therefore, improving our understanding of the concerns of women with epilepsy through research can help midwives and reproductive healthcare professionals to provide services and interventions to assist women with epilepsy. According to the findings of studies, the process of pregnancy in epileptic women can be influenced by the illness and drug therapy as well as their level of perceptions and experiences (often under the socio-cultural backgrounds) as a risk that may pose a threat to their health and their fetus' health $(4,10)$. On the other hand, based on the experience of the researcher with experience in the field of health, there has been knowledge and performance gaps in epileptic women and in the health sector related to this group of women. Since the issue of pregnancy concerns is subjective and abstract and it is influenced by the complex factors of the value system, culture and religion of Iranian society, it was necessary to conduct qualitative research. The aim of this study was to explore the pre and post pregnancy needs of epileptic women.

\section{Material and Methods}

\subsection{Study design}

Since the aim of this study was to explore the reproductive healthcare needs, concerns and understandings of women with epilepsy before, during and after childbirth, a qualitative study using a conventional content analysis was conducted.

\subsection{Sampling methods}

Purposive sampling and data collection were conducted from April to December 2015 until data saturation was reached. The Inclusion criteria includes the following: (1) married women with epilepsy in the reproductive age (15-45 years) and without cognitive impairment based on the diagnosis of a neurologist, and (2) the workers of the Iranian Epilepsy Association, neurologists and gynecologists with more than 5 years of experience.

\subsection{Data Collection and Analysis}

Sampling was carried out continuously from women with epilepsy at the Neurology Clinic of the Imam Hossein Teaching Hospital and Iranian Epilepsy Society. Data were collected using recorded and individual semi-structured interviews in private places convenient to the participants. The interviews were started using a general question such as 'Could you describe your problems during pregnancy?' In addition, some questions were asked regarding pregnancy issues affected by epilepsy before, during and after pregnancy. Probing questions were asked to improve the depth of the interviews, such as 'Could you explain it more'? 'Could you provide an example of it?' In addition, branching questions were asked to follow the participants' perspectives such as 'Why?' 'What factors affected this problem'? What factors hindered this problem'? The duration of the interviews lasted between 20 and 90 minutes with the participants chosen using a purposive method until data saturation was reached. Finally, sixteen individual 
interviews were performed with eleven married women with epilepsy, one neurologist, one gynecologist and three staff members of the Iranian Epilepsy Association.

\subsection{Data Analysis}

The data collection and analysis were performed concurrently based on the method suggested by Graneheim and Lundman (13). The interviews were transcribed verbatim and read several times to obtain a more complete understanding. Next, phrases and sentences related to the study phenomenon were highlighted and coded. The codes were compared together in terms of similarities and differences and sorted into subcategories and categories. Data saturation was achieved in the 10th interview for researchers, and one additional interview was conducted to ensure there would be no new data after that. Interviews with five healthcare professionals led to the development of new categories and subcategories. To ensure data saturation, two extra interviews were conducted that led to the development of themes and latent patterns in the data. MAXQDA software 2010 was used for data management.

\subsection{Trustworthiness}

Rigor was ensured using the criteria suggested by Guba and Lincoln including credibility, confirmability, dependability and transferability. For credibility, integration of data collection methods such as interviews and field notes, integration of data sources such as women with epilepsy and healthcare providers, and integration of data collection places such as clinics, hospital and the epilepsy association were considered. Also, maximum variation in sampling and member checking were conducted. For dependability, the code-recode method was carried out. Peer checking helped with the rectification of codes by four researchers who were familiar with qualitative methods. For transferability, in spite of maximum variation in sampling, four women with epilepsy who were not involved in this study were requested to give their comments about the results of the data analysis.

\subsection{Ethical Consideration}

This study was one part of a larger study on the reproductive health needs of women with epilepsy. Before the interviews, the participants were informed of the study aim and method. Permission to tape-record their voices was then obtained. They were ensured of the confidentiality of the collected data and their anonymity throughout the study. Those who willingly agreed to take part in this study signed the written informed consent form. The protocol of this study was confirmed by the ethics committee affiliated with Shahid Behesti University of Medical Sciences, International Campus (Decree number: IR.SBMU.IASB.REC).

\section{Results}

In this study, 11 married women with epilepsy who had no cognitive disorders diagnosed by the neurologist, participated in this study. The range of their age was 15-45 years and the majority of them had high school education. They were mainly housewives and multiparous. Their social and economic conditions were in the weak and intermediate levels. The other participants were one neurologist, one gynecologist and three staff members of the Iranian Epilepsy Association who had more than five years' work experience. The data analysis led to the development of seventy-one initial codes, eight subcategories and two categories as follows: 'resilience against threats to safe pregnancy' and 'adverse experiences under supportive systems' disruption' (Table 1). The categories and subcategories were described with more detail as follows.

Table 1. Results of qualitative content analysis, the concerns of women with epilepsy about pregnancy:

\begin{tabular}{|c|c|c|}
\hline Theme & Categories & Subcategories \\
\hline \multirow[t]{8}{*}{$\begin{array}{l}\text { Concerns about } \\
\text { unbridled pregnancy }\end{array}$} & \multirow[t]{4}{*}{$\begin{array}{l}\text { Resilience against safe } \\
\text { pregnancy threats }\end{array}$} & $\begin{array}{l}\text { Real physical complications and perceived mental conditions } \\
\text { due to unwanted pregnancies }\end{array}$ \\
\hline & & The predisposing factors of anxiety related to safe pregnancy \\
\hline & & Perceived consequences of pregnancy \\
\hline & & $\begin{array}{l}\text { The approach to encounter perceived consequences of } \\
\text { pregnancy }\end{array}$ \\
\hline & \multirow{4}{*}{$\begin{array}{l}\text { Adverse experiences } \\
\text { under inefficient } \\
\text { supportive systems }\end{array}$} & The insufficiency of reproductive healthcare services \\
\hline & & Doubt about the advantages and disadvantages of breastfeeding \\
\hline & & Stigma as a block to the treatment of the postpartum depression \\
\hline & & $\begin{array}{l}\text { Playing the motherhood role under the shadow of self-esteem } \\
\text { to lack of self-esteem }\end{array}$ \\
\hline
\end{tabular}




\subsection{Resilience against threats to safe pregnancy}

The majority of the participants should be under close monitoring in terms of the condition of epilepsy and medication therapy. Being under control was described as an uncomfortable feeling. Half of the participants experienced unwanted pregnancies and their inappropriate consequences. Generally, all participants were deeply concerned regarding the impact of epilepsy and medication therapy on their own and fetus' health, which was higher than their concerns about unwanted pregnancies. Moreover, the participants used the resilience approach to face their perceived worries and concerns. The related subcategories were 'real physical complications and perceived (mental) conditions due to unwanted pregnancies', 'the predisposing factors of anxiety related to safe pregnancy', 'perceived consequences of pregnancy', 'the approach to encounter perceived consequences of pregnancy' and 'the family apprehension of the experience of seizure in pregnancy'.

3.1.1. Real physical complications and perceived (mental) conditions due to unwanted pregnancies:

About half of the participants' pregnancies were unwanted and unplanned and mostly, they had experienced adverse pregnancy outcomes such as anemia, congenital anomalies, spontaneous abortion and increase in the intensity and frequency of seizures during pregnancy. For example, one of the participants who had a history of unwanted pregnancy that resulted in induced abortion said "In the third month of my previous pregnancy, they said that my baby had anomalies and hydrops and should have been aborted" (P 10, 36 years old, Gravid 3, Duration of disease: 24 years, master's degree education). This group of mothers were under immense stress due to experiencing the adverse conditions in their previous pregnancies and the pregnancies of others, that had led to feelings of guilt because of late referral to the physician or taking medication during pregnancy. Participant 4 stated about her last pregnancy: "If I knew that I was pregnant, I would not have hesitated to go to the doctor and when the physician changed my drugs, I got worried about the teratogenicity effects of drugs that I had used during my pregnancy." (P 4, 40 years old, Duration of disease: 35 years, Gravid: 1, elementary education). Also, some of them were worried about the control of their seizures during pregnancy because of the drug change. Participant 11 said "I used to take 6 tablets per day and in spite of that, sometimes I had loss of consciousness, and now that I am pregnant and taking less drugs, I am worried about the lack of the control of my seizures" (P 11, 32 years old, Duration of disease: 11 years, Gravid: 3 , guidance school education).

3.1.2. The predisposing factors of anxiety related to safe pregnancy:

The majority of the nulliparous women with epilepsy were worried that epilepsy hindered a safe pregnancy. In spite of having a relatively appropriate physical condition for pregnancy and family members' insistence, the majority of the women were afraid to become pregnant. One of the participants without history of pregnancy said: despite the fact that I like children so much, and the physician's recommendation on the safety of my pregnancy, I am so scared of pregnancy and avoid it." (P 7, 21 years old, Duration of disease: 8, Gravid: 0, diploma degree education). Being afraid of pregnancy stemmed from the experiences of other women with epilepsy regarding pregnancy. In this regard, a 36-year-old woman that had an understanding of adverse experiences in her cousin's pregnancy stated "first, I was so worried about pregnancy and the child's wellbeing because my epileptic cousin had a child suffering from a brain disorder." (P 10, 36 years old, Gravid 3, Duration of disease: 24 years, master's degree education). Some women who needed to prevent pregnancy with the aim of controlling epilepsy had a suffering understanding of planned pregnancy. One said about these worries "I like getting pregnant but my physician recommended me to use contraceptive methods and also, I had to be monitored. Commuting to the neurologist's office is too agonizing for me." (P 3, 24 years old, Duration of disease: 19 years, Gravid: 0, 5 years married, elementary education). The women were also worried that they might lose the chance for pregnancy due to the progression of the disease and getting old. A woman said: "I am always thinking of when my disease gets cured and my medication is changed. I am worried that I get older and I cannot get pregnant." (P 3, 24 years old, Duration of disease: 19 years, Gravid: 0, 5 years married, elementary education). Also, those women with lower socio-economic conditions were in fear of losing their husbands due to the male-dominated condition of the family and the significance of the child in stabilizing the family. In this regard, participant 4 with history of infertility for six years said this "My husband always said: 'this is your fault'. My husband's family always reminded me of my epileptic disease. The family wanted to find him a new wife." (P 4, 40 years old, Duration of disease: 35 years, Gravid: 1, elementary education). 3.1.3. Perceived consequences of pregnancy:

All pregnant women with epilepsy were worried about the consequences of epilepsy during pregnancy especially those who experienced it in previous pregnancies. Participant 10 with two experiences of losing the child due to unplanned pregnancies stated this: "During the pregnancy, I was thinking of its failure, but the physician would ensure me that it had no relationship to the previous pregnancy." (P 10, 36 years old, Gravid 3, Duration of disease: 24 years, master's degree education). Another participant that had the experience of late recovery after cesarean section said: "I am scared that I may not get out of the operating room or my kids are hurt." (P 11, 32 years old, Duration of disease: 11 years, Gravid: 3, guidance school education). Another worry of the participants was the fear 
that epilepsy was inherited to their unborn child. Some participants stated this: "I am scared that perhaps my disease is inherited to my child" (P 11, 32 years old, Duration of disease: 11 years, Gravid: 3, guidance school education). Another participant without the experience of pregnancy said: "I do not know how much my disease is hereditary. I do not want my child to suffer from epilepsy like me." (P 3, 24 years old, Duration of disease: 19 years, elementary education). The women had doubts about medication therapy in spite of the education they received about it. Doubts about medication therapy discouraged them to get pregnant in the future. In case of pregnancy, they suffered from adherence to medication therapy. One of the participants with college education who had just given birth said: "My physician said that medication had no or had little effect on the child, but I felt guilt. Also, I could not avoid taking the drugs, in case my seizures might return" (P 10, 36 years old, Gravid 3, Duration of disease: 24 years, master's degree education). Another participant in her third pregnancy said: "I am scared using this drug [Phenytoin], but I put my trust in God to prevent future incidents" (P 1, 37 years old, Duration of disease: 17 years, Gravid: 3, elementary education). On the other hand, nulliparous women did not get pregnant due to the necessity of adherence to medication therapy. A participant said: "It is said that the drugs can affect the child's neural development; therefore, I dare not get pregnant." (P 7, 21 years old, Duration of disease: 8, Gravid: 0, diploma degree education). Another concern of the women with epilepsy was their worries and family members' concerns about the recurrence of the disease during pregnancy. This condition (Fear of recurrence of seizures) intensified anxiety in the women's family and relatives. A participant said "My family members and husband frequently make phone calls to me and tell me to take care of myself and not become angry" (P 1, 37 years old, Duration of disease: 17 years, Gravid: 3, elementary education). "My husband frequently calls me and ...I did not like them to get so worried about me and fuss about me so much." (P 10, 36 years old, Gravid 3, Duration of disease: 24 years, master's degree education). The women's concerns about the recurrence of epilepsy during pregnancy was related to the probable effect of seizure on abortion and fetal complications. A woman with a history of 6 years of infertility who experienced the exacerbation of her seizures in the second semester of pregnancy said "I had frequent seizures during my last pregnancy and I had worries about abortion and congenital malformations in my baby" (P 4, 40 years old, Duration of disease: 35 years, Gravid: 1, elementary education). The women were also worried about the birth of a child with mental disability. For instance, participant 10 said "I said to the physician that my age or disease might affect the child. I was worried that my child may have had mental retardation." Moreover, complications during the cesarean section such as seizure incidents during the surgery or no recovery after the cesarean section made the women concerned about pregnancy. "I am scared about the interactions between epileptic drugs and anesthetic drugs during the surgery that I do not recover at all from anesthesia" (P 1, 37 years old, Duration of disease: 17 years, Gravid: 3, elementary education). "I am scared that I have seizure incidents during the surgery and my own health or the child's health is endangered." (P 11, 32 years old, Duration of disease: 11 years, Gravid: 3, guidance school education).

\subsubsection{The approach to encounter perceived consequences}

As a result, it led to additional concerns of pregnancy. The women used a series of cognitive approaches to reduce their worries of pregnancy. These approaches included asking for general anesthesia during the surgery, because of the fear of seizures, genetic tests and unnecessary and costly fetal health tests at the request of the mother or even avoiding pregnancy. An employee of the Iranian Epilepsy Association with 20 years of work experience said: "The women with epilepsy have obsessions regarding their children's health. A woman with a low economic condition asked for frequent and unnecessary para-clinic examinations to ensure her child's health." (A worker of the Iranian Epilepsy Association, 45 years old). Another woman who performed genetic tests before marriage said: "I insisted that amniocentesis tests are performed for my child's health, in spite of the previous examinations that confirmed my child health status." (P 10, 36 years old, Gravid 3, Duration of disease: 24 years, master's degree education).

\subsection{Adverse experiences under inefficient supportive systems}

According to the international literature, pregnancy in women with epilepsy was mostly accompanied with desired consequences (4). However, in this study, many women experienced undesired consequences of pregnancy due to the high rates of the cesarean section. A lack of presence of appropriate supports for pregnant women with epilepsy including family's knowledge, expert healthcare professions and empowerment to encounter difficulties during pregnancy led to pregnancy complications. This category consisted of the following subcategories: 'the insufficiency of reproductive healthcare services for women with epilepsy', 'doubt about the advantages and disadvantages of breastfeeding', 'stigma as a block to the treatment of postpartum depression' and 'playing the motherhood role under the shadow of self-esteem to lack of self-esteem'.

3.2.1. The insufficiency of reproductive healthcare services for women with epilepsy:

The participants mostly had a cesarean section. Therefore, the rates of hospitalization for a long time after childbirth, atonic uterus and bleeding, and pain after the surgery were increased. Also, negligence by healthcare professionals 
during the provision of care after childbirth was reported by the participants. A participant said "The day after the surgery, my physician angrily said: 'come on, get out of the bed and walk'... I said that I was unable to walk ....I cannot remember what happened next.. I think that I experienced falling down in the hall and also a seizure." This person describes her mental barriers to ask for help as follows: "I could not ask anyone to help me to go to the toilet, because I was shy.” (P 10, 36 years old, Gravid 3, Duration of disease: 24 years, master's degree education).

In addition, no participants had received adequate and appropriate prenatal consulting. Most specialists did not prescribe the appropriate dose of folic acid that is recommended in scientific resources for epileptic women (4 to 5 $\mathrm{mg}$ per day). For example, one of the participants who had received prenatal care, in response to the question on how much folic acid she took daily, said "I take a $1 \mathrm{mg}$ tablet daily" and she had been taking it up to the seventh month of pregnancy (P 1, 37 years old, Duration of disease: 17 years, Gravid: 3, elementary education).

3.2.2. Stigma as a block to the treatment of the postpartum depression:

In this study, a quarter of the women with epilepsy after childbirth suffered from chronic depression. One of the participants described the symptoms of depression after childbirth as follows: A desire and attempt to choke the kid, dual desire and feelings of hatred toward the child. She continued: "After the birth of my child, I had the feeling of a desire toward fire and breaking glass. I would enjoy choking my child. I pressed her nostrils to make her choke..." (P 2, 36 years old, Duration of disease: 23 years, Gravid: 2, guidance school education). Being worried about and afraid of losing the child encouraged the women to hide their depression symptoms for a couple of months after childbirth. A woman with a history of 6 years of infertility, states: "I did not talk about my symptoms to anybody. I was scared that they might separate my child from me." (P 4, 40 years old, Duration of disease: 35 years, Gravid: 1, elementary education). When family members found out about the symptoms, they referred them to the neurologist rather than the psychiatrist. Also, due to the stigma of depression, they disagreed with their hospitalization. "The physician said to me I should be hospitalized, but my husband disagreed and said that our relatives will say that I am crazy...." (P 4, 40 years old, Duration of disease: 35 years, Gravid: 1, elementary education).

3.2.3. Doubt about the advantages and disadvantages of breastfeeding:

Most women with epilepsy were doubtful about the advantages and disadvantages of breastfeeding the newborn. The neurologist forbade them to breast feed due to taking anticonvulsant drugs. However, they were allowed to choose between breast-feeding and formula feeding based on their economic conditions. For instance, a neurologist said "there is no agreement on breast-feeding between neurologists. I describe the advantages and disadvantages of breast-feeding to parents and they make decisions based on their economic condition." (Neurologist, 50 years old, 10 years work experience). Some participants shared their worries as follows: "I was told before that I could breastfeed my child. However, a neurologist said that I should change the drugs, I did not know if they could reach the child through the milk." (P 9, 30 years old, Duration of disease: 12 years, Gravid: 1, diploma education). Another participant said: "The gynecologist said that I could breast-feed the child, but I am scared, because this amount of drug is for an adult and may reach the child through my milk and harm him." (P 5, 19 years old, Duration of disease: 6 years, Gravid: 1, diploma degree).

3.2.4. Playing the motherhood role under the shadow of self-esteem and lack of self-esteem:

The findings of this study showed that the degree of self-esteem for taking the motherhood role depended on the severity of the disease and appropriate support by family members. For instance, a participant who experienced seizure twice in one month said "I cannot touch my child, in case I have a seizure and the child falls down. So far, my mother has taken care of my child.” (P 4, 40 years old, Duration of disease: 35 years, Gravid: 1, elementary education). Another participant who had controlled her epilepsy said: "I do all my child care now...I used my mother's experiences and learned how to take care of the child....however I carry my child using a carriage." (P 10, 36 years old, Gravid 3, Duration of disease: 24 years, master's degree education)

\section{Discussion}

The data analysis led to the development of two categories of 'resilience against threats to safe pregnancy' and 'adverse experiences under inefficient supportive systems. The women with epilepsy mostly perceived threats to the safety of their pregnancies. The nulliparous women avoided pregnancy due to the undesired consequences of pregnancy. Therefore, Turner et al., in 2008 showed that nulliparous women with epilepsy achieved higher scores in the fear of pregnancy than other women (14). In addition, the participants had a sense of agonizing pregnancy under medical supervision. It was found that nulliparous women had an undesirable understanding of preconception care. In fact, impossibility of the estimation of the appropriate time for pregnancy and conception were the reasons for the feeling of suffering (14). Winterbottom, in 2012 said that many women with epilepsy preferred to get pregnant in a more normal and comfortable time (15). Also, a lack of the provision of appropriate conditions for safe pregnancy was described by some participants as the factor that endangered the stability of marital life, especially in maledominated families with a low economic-social condition. In a pronatalist society, the stigma of infertility can 
undermine women's empowerment and achievements. The stigma of infertility has a more devastating effect on illiterate or unemployed women (16). Especially in developing countries, the majority of such women experience the negative consequences of the marital instability and stigma (17). Another concern of pregnant women with epilepsy was the undesired maternal and fetal consequences, which was mainly caused by the perception of the effects of the disease on pregnancy and medication adherence. In spite of medication adherence by most women, the concern about the teratogenicity of the drugs made the women feel both suffering and guilt due to medication adherence. Similarly, the study of Widnes et al. showed that women with epilepsy were worried about the teratogenicity of anticonvulsion drugs. Also, their anxiety was intensified if the dose of the drugs was increased during pregnancy (18). The study of Lee, et al. showed that the exaggerated perception among women with epilepsy with regard to drug's effects on pregnancy caused the women to discontinue medication (19). In other words, if there is no balance between understandings of the risk and the improvement of self-esteem, the perceived risk of pregnancy is increased, which can lead to avoiding pregnancy or the feelings of shame and selfishness $(15,18)$. The participants used cognitive flexibility and perception of the risk for reducing their mental stress. They used strategies such as avoiding becoming pregnant and taking unnecessary tests for the fetus' health. Sometimes, they used spiritual powers to reduce their worries. Similarly, the results of the study showed that most women with epilepsy were afraid of the effects of drugs and genetic inheritance on the health of their fetus. Many of them believed in the power of praying in the health of the child (20). Additionally, the undesired consequences of previous unplanned pregnancies such as abortion, fetal malformation and the occurrence of undesired consequences in other women with epilepsy intensified the participants' worries. Carolan, et al. stated that pregnant women's perceptions of the risk were related to their previous experiences (21) and their personal values that diverted the pregnancy from its normal process toward inappropriate and unnecessary medical interventions (22). In the last decade, in spite of the advancement of technologies in the field of midwifery, women's emotional support and personal education has been ignored. In spite of access to information from the internet and other sources, the improvement of personal education and emotional support to the women and their families (23) by support sources are emphasized (24).

In this study, one quarter of the participants reported a history of depression after childbirth. They received no support from their families, and therefore hid the symptoms of depression. Also, they were hindered from receiving appropriate psychological care for a long time after childbirth due to the families' perceptions of the stigma of depression. Other studies showed that prevalence of depression after childbirth is $25-37 \%(25,26)$. Women with depression hide their symptoms and are not inclined to receive mental care due to the perceived stigma (27). In a study in England, in spite of perceiving the stigma related to depression, it was found that patients and their family members are willing to receive care because depression and its treatment are accepted by society (28). In the present study, about half of the women with epilepsy mentioned a history of unwanted pregnancy, which was associated with anemia, congenital malformations, spontaneous abortions and increased duration and frequency of seizure. Furthermore, they were concerned about medication changes during pregnancy and a lack of the control of the disease. Other studies showed that one quarter or half of pregnant women with epilepsy had unwanted pregnancies $(29,30)$. Clearly, such women are hindered from receiving appropriate preconception counseling, disease control and medication therapy before pregnancy. Therefore, the adverse consequences of the pregnancy for the mother and fetus are increased due to an inappropriate control of the disease and lack of adherence to medication $(31,32)$. Conversely, a study by Abe, et al. showed that no differences in the consequences of pregnancy for the mother and fetus were reported between the group of unwanted pregnant mothers with epilepsy and the other group, in spite of frequent seizures and a lack of the mothers' adherence to medication (33). The probable reason for such a finding can be the place of sampling, which was a referral teaching hospital with a prevalence of $10.7 \%$ for congenital malformations. This prevalence rate is higher than the rate reported for the normal population and also those reported in the studies of women with pregnancy (4.2-6.7\%). In this study, gynecologists considered cesarean section the preferred method of childbirth for women with epilepsy, which also has increased postpartum complications. On the other hand, the participants were worried about the probability of drug interactions between antiepileptic and anesthetic drugs and the occurrence seizure during surgery and not recovering consciousness. McAuley et al. reported that the cognitive concerns of mothers of medication therapy during and after childbirth were the reasons for stopping medication therapy arbitrarily (34). In addition, a lack of receiving postpartum care for their underlying disease made the participants resentful. One of them reported a falling down incident in the toilet due to the physician's insistence for walking soon after the childbirth and not asking for help from nurse assistances. In line with our findings, the study of Walsh-Gallagher et al., in a qualitative study on disabled women, showed that midwives after the childbirth ignored patients' worries and mental concerns. Some participants stated that they were under pressure by the healthcare staff to take a shower after the childbirth, which led to them falling down (20). Another concern by the women was the possibility of breast-feeding after the childbirth. In other words, they were 
doubtful about it in spite of receiving education from the physician. Moreover, inconsistencies in physicians' perspectives about breastfeeding intensified the women's concerns. Some studies on the adverse effects of anticonvulsion drugs on the newborn's brain development found that they had no effects on the IQ and talking abilities of six-year-old children (35). However, breastfeeding is safe in women undergoing single drug medication. Therefore, all physicians involved in the care process of women with epilepsy need to encourage them to breast-feed (36). A limitation of this study was a lack of generalizability of its findings to women in other cultures and contexts. However, a maximum variation in sampling in terms of age and the economic and social levels, helped to reduce this limitation.

\section{Conclusions}

The women in this study were concerned about issues that might endanger safe pregnancy. Also, they worried about losing the opportunity of pregnancy, which could threaten marital life. Therefore, they tried to relieve their worries and concerns using cognitive approaches as much as they could. They also suffered from problems during childbirth and after that, due to a lack of support systems by the family and society and low self-efficacy. In this respect, those two-categories in this study were related to the concerns about unbridled pregnancy.

\section{Acknowledgments:}

This article was one part of the first author's $\mathrm{PhD}$ dissertation in reproductive health supported financially by Shahid Beheshti University of Medical Sciences, Tehran, Iran. Also, the authors would like to thank the participants, the deputy of research at the university, Faculty of Nursing and Midwifery, the Iranian Epilepsy Association and the teaching hospital's staff for their collaboration in this research project.

\section{Conflict of Interest:}

There is no conflict of interest to be declared.

\section{Authors' contributions:}

All authors contributed to this project and article equally. All authors read and approved the final manuscript.

\section{References:}

1) Longo DL, Harrison TR, Longo Dan L, Fauci A, Kasper DL, Hauser S L, et al. Harrison's principles of internal medicine. 18 ed ed. New York: McGraw-Hill Medical; 2012.

2) Viinikainen K, Heinonen S, Eriksson K, Kälviäinen R. Community - based, Prospective, Controlled Study of Obstetric and Neonatal Outcome of 179 Pregnancies in Women with Epilepsy. Epilepsia. 2006; 47(1): 186-92. doi: 10.1111/j.1528-1167.2006.00386.x. PMID: 16417548.

3) Fairgrieve SD, Jackson M, Jonas P, Walshaw D, White K, Montgomery TL, et al. Population based, prospective study of the care of women with epilepsy in pregnancy. BMJ. 2000; 321(7262): 674-5. doi: 10.1136/bmj.321.7262.674.

4) Cunningham G, Leveno KJ, Bloom SL, Spong CY, Dashe JS. Williams Obstetrics. 24th edition; 2014.

5) Kochen S, Salera C, Seni J. Pregnant women with epilepsy in a developing country. Open Neurol J. 2011; 5: 63-7. doi: 10.2174/1874205X01105010063. PMID: 22046203 PMCID: PMC3204418.

6) Thompson D, Thomas H, Solomon J, Nashef L, Kendall S. Chronic illness, reproductive health and moral work: women's experiences of epilepsy. Chronic Illn. 2008; 4(1): 54-64. doi: 10.1177/1742395307086696. PMID: 18322030.

7) Davis AR, Pack AM, Kritzer J, Yoon A, Camus A. Reproductive history, sexual behavior and use of contraception in women with epilepsy. Contraception. 2008; 77(6): 405-9. doi: 10.1016/j.contraception.2008.02.002. PMID: 18477488.

8) Dennis AJ. Identifying and responding to the reproductive decision-making needs of women with epilepsy. Boston University; 2012.

9) Weckesser A, Denny E. Women living with epilepsy, experiences of pregnancy and reproductive health: A review of the literature. Seizure. 2013; 22(2): 91-8. doi: 10.1016/j.seizure.2012.11.001. PMID: 23182977.

10) Helbig KL, Bernhardt BA, Conway LJ, Valverde KD, Helbig I, Sperling MR. Genetic risk perception and reproductive decision making among people with epilepsy. Epilepsia. 2010; 51(9): 1874-7. doi: 10.1111/j.1528-1167.2009.02507.x. PMID: 20163441.

11) Gaffield ME, Culwell KR, Lee CR. The use of hormonal contraception among women taking anticonvulsant therapy. Contraception. 2011; 83(1): 16-29. doi: 10.1016/j.contraception.2010.06.013. PMID: 21134499. 
12) Veiby G, Daltveit AK, Schjølberg S, Stoltenberg C, Øyen AS, Vollset SE, et al. Exposure to antiepileptic drugs in utero and child development: A prospective population - based study. Epilepsia. 2013; 54(8): 1462-72. doi: 10.1111/epi.12226. PMID: 23865818, PMCID: PMC3766256.

13) Graneheim UH, Lundman B. Qualitative content analysis in nursing research: concepts, procedures and measures to achieve trustworthiness. Nurse educa today. 2004; 24(2): 105-12. doi: 10.1016/j.nedt.2003.10.001. PMID: 14769454.

14) Turner K, Piazzini A, Franza A, Canger R, Canevini MP, Marconi AM. Do Women with Epilepsy Have More Fear of Childbirth During Pregnancy Compared with Women without Epilepsy? A Case - Control Study. Birth. 2008; 35(2): 147-52. doi: 10.1111/j.1523-536X.2008.00228.x. PMID: 18507586.

15) Winterbottom JB. Women with epilepsy preparing for pregnancy: a qualitative analysis. University of Liverpool. 2012. Available from: http://ethos.bl.uk/OrderDetails.do?uin=uk.bl.ethos.603556.

16) Remennick L. Childless in the land of imperative motherhood: Stigma and coping among infertile Israeli women. Sex roles. 2000; 43(11-12): 821-41. doi: 10.1023/A:1011084821700.

17) Dyer SJ, Abrahams N, Hoffman M, van der Spuy ZM. Men leave me as I cannot have children': women's experiences with involuntary childlessness. Hum Reprod. 2002; 17(6): 1663-8. doi: 10.1093/humrep/17.6.1663. PMID: 12042295.

18) Widnes SF, Schjøtt J, Granas AG. Risk perception and medicines information needs in pregnant women with epilepsy-A qualitative study. Seizure. 2012; 21(8): 597-602. doi: 10.1016/j.seizure.2012.06.007. PMID: 22762859.

19) Lee SM, Nam HW, Kim EN, Shin DW, Moon HJ, Jeong JY, et al. Pregnancy-related knowledge, risk perception, and reproductive decision making of women with epilepsy in Korea. Seizure. 2013; 22(10): 834-9. doi: 10.1016/j.seizure.2013.07.002. PMID: 23890718.

20) Walsh-Gallagher D, Sinclair M, Mc Conkey R. The ambiguity of disabled women's experiences of pregnancy, childbirth and motherhood: a phenomenological understanding. Midwifery. 2012; 28(2): 15662. doi: 10.1016/j.midw.2011.01.003. PMID: 21570753.

21) Carolan MC. Towards understanding the concept of risk for pregnant women: some nursing and midwifery implications. J Clin Nurs. 2009; 18(5): 652-8. doi: 10.1111/j.1365-2702.2008.02480.x. PMID: 18705630.

22) Oakley A. Social consequences of obstetric technology: the importance of measuring "soft" outcomes. Birth. 1983; 10(2): 99-108. doi: 10.1111/j.1523-536X.1983.tb01408.x.

23) Welch L, Miller L. Emotional and Educational Components of Pregnancy. Glob libr women's med. 2008.

24) Qiang JK, Nyhof-Young J, D'Souza R, Bui E. Support systems of women with epilepsy in pregnancy: A retrospective needs assessment. Seizure. 2016; 36: 1-3. doi: 10.1016/j.seizure.2015.12.017.

25) Galanti M, Newport DJ, Pennell PB, Titchner D, Newman M, Knight BT, et al. Postpartum depression in women with epilepsy: influence of antiepileptic drugs in a prospective study. Epilepsy \& Behavior. 2009; 16(3): 426-30.doi: 10.1016/j.yebeh.2009.07.009.

26) Bjørk MH, Veiby G, Reiter SC, Berle JØ, Daltveit AK, Spigset O, et al. Depression and anxiety in women with epilepsy during pregnancy and after delivery: A prospective population - based cohort study on frequency, risk factors, medication, and prognosis. Epilepsia. 2015; 56(1): 28-39. doi: 10.1111/epi.12884. PMID: 25524160.

27) Robertson E, Lyons A. Living with puerperal psychosis: A qualitative analysis. Psychology and Psychotherapy. 2003; 76(4): 411-31. doi: 10.1348/147608303770584755.

28) Edwards E, Timmons S. A qualitative study of stigma among women suffering postnatal illness. Journal of Mental Health. 2009. doi: 10.1080/09638230500271097.

29) Bjørk MH, Veiby G, Engelsen BA, Gilhus NE. Depression and anxiety during pregnancy and the postpartum period in women with epilepsy: A review of frequency, risks and recommendations for treatment. Seizure. 2015; 28: 39-45. doi: 10.1016/j.seizure.2015.02.016. PMID: 25777784.

30) Pashley S, O'Donoghue MF. The safety of anti-epileptic drug regimens: a qualitative study of factors determining the success of counselling women before conception. J Fam Plann Reprod Health Care. 2009; 35(3): 153-6. doi: 10.1783/147118909788708002. PMID: 19622204.

31) Thomas SV. Managing epilepsy in pregnancy. Neurol India. 2011; 59(1): 59-65. doi: 10.4103/00283886.76860. PMID: 21339661.

32) Meador K, Pennell P, Harden C, Gordon J, Tomson T, Kaplan P, et al. Pregnancy registries in epilepsy a consensus statement on health outcomes. Neurology. 2008; 71(14): 1109-17. doi: 10.1212/01.wnl.0000316199.92256.af. PMID: 18703463. 
33) Abe K, Hamada H, Takahiro Yamada T, Obata-Yasuoka M, Minakami H, Yoshikawa H. Impact of planning of pregnancy in women with epilepsy on seizure control during pregnancy and on maternal and neonatal outcomes. Seizure. 2014; 23(2): 112-6. doi: 10.1016/j.seizure.2013.10.003. PMID: 24183922.

34) McAuley JW, Patankar C, Lang C, Prasad M. Evaluating the concerns of pregnant women with epilepsy: a focus group approach. Epilepsy Behav. 2012; 24(2): 246-8. doi: 10.1016/j.yebeh.2012.03.014. PMID: 22560188.

35) Meador KJ, Baker GA, Browning N, Cohen MJ, Bromley RL, Clayton-Smith J, et al. Breastfeeding in children of women taking antiepileptic drugs: cognitive outcomes at age 6 years. JAMA pediatrics. 2014; 168(8): 729-36. doi: 10.1001/jamapediatrics.2014.118. PMID: 24934501 PMCID: PMC4122685.

36) Harden CL. Beneficial or neutral effect of breastfeeding on cognitive outcomes in children of mothers with epilepsy? JAMA pediatrics. 2014; 168(8): 699-700. doi: 10.1001/jamapediatrics.2014.420. PMID: 24934300 . 